\title{
High Temperature Effect on Root Absorption
}

\author{
Mohammad AFFAN Fajar Falah", Takahiro WAJIMA*, Daisuke YASUTAKE**, \\ Kouta HIDAKA* ${ }^{*}$ and Masaharu KITANO**. \\ "Graduate School of Agriculture, Kochi University, Monobe Otsu 200, Nankoku, Kochi 783-8502, Japan \\ " Faculty of Agriculture, Kochi University, Monobe Otsu 200, Nankoku, Kochi 783-8502, Japan \\ "'Graduate School of Bioresource and Bioenvironmental Sciences, Kyushu University, \\ Hakozaki 6-10-1, Higashi-ku, Fukuoka 812-8581, Japan
}

\begin{abstract}
Dynamic and simultaneous evaluation of rates of water and nutrients uptake by intact roots was enabled in the hydroponic systems. Rates of water and nutrients uptake were evaluated simultaneously on the basis of time courses analyses of water balance and nutrients balance in the systems, and these also enabled estimation of nutrients concentration in xylem sap. Root hydraulic conductance was also measured by using the high pressure flow meter with a pressure tank at different root temperatures.

Water and nutrients uptake rates varied depending on irradiance. Just after the start of treatment with high root temperature, water and nutrients uptake was activated, but several days after, the high temperature treatment brought significant depression in water and nutrients uptake rates. Lower nutrient concentration in xylem sap was also found under the higher root temperatures, and this suggested that the high root temperature retarded active nutrients transport. Furthermore, growth depression and color change in roots were caused several days after the start of the high root temperature treatment. Those results suggest that short-term and long-term effects of the high root temperature appeared in different manners through different processes.

Key words : High temperature, Root water uptake, Root nutrients uptake.
\end{abstract}

\section{Introduction}

Root physiological functions play an important role in the plant production system under global climate change, but this has received less attention until recently because roots are usually underground and difficult to study. Root physiological functions are strongly influenced by environmental factors, especially composition and concentration of the soil solution, soil moisture, soil aeration and soil temperature (Kramer and Boyer, 1995).

Root water uptake decreased at low root temperature, and root resistance to water movement through the roots increased. On the other hand, less is known about the effects of high temperature on water and nutrients absorption (Kramer and Boyer, 1995). Poor information about root responses to high temperature is caused by difficulties in measurement of physiological functions of intact roots in plant production systems. This study deals with effects of high temperature on root physiological functions by using newly developed systems and methods for measurements of water and nutrients uptake by intact roots.

\section{Materials and Methods}

\subsection{Evaluation of water and nutrient uptake rates}

The NFT system was newly developed for dynamic and simultaneous evaluations of water and nutrients uptake rate by roots in the greenhouse (Yasutake et al., 2004). Dynamics of water uptake rate $\left(Q \mathrm{w}, \mathrm{mL} \mathrm{h}^{-1}\right)$ was evaluated based on dynamic analysis of water balance in the NFT system where the nutrient solution can be automatically supplied by on-off action of the solenoid valve depending on water uptake by roots. Rates of nutrients uptake $(Q \mathrm{~m}$, $\left.\mathrm{g} \mathrm{h}^{-1}\right)$ was also evaluated based on dynamic analysis of nutrients balance in the NFT system, where the nutrient solution was sampled every hour and change in nutrient concentration was measured by using the soil-plant chemical analyzer (SPCA-6210, Shimadzu, Kyoto, Japan).

In the pot culture system (soilless culture), water and nutrients uptake rates were also evaluated on the basis of water and nutrients balance in the pot by applying the photometric method of the chemical analyzer.

These simultaneous evaluations of water and 
nutrient uptake rates enabled evaluation of nutrient concentration in xylem sap ( $\left.[\mathrm{M}] \mathrm{xy}, \mathrm{gL}^{-1}\right)$ by dividing the nutrient uptake rate by the water uptake rate.

Furthermore, root hydraulic conductance ( $L p$, mmols ${ }^{-1} \mathrm{MPa}^{-1}$ ) was measured at different root temperatures of 10,25 and $40^{\circ} \mathrm{C}$ by using the high pressure flow meter with a pressure tank.

\subsection{Plant materials}

Tomato plants ( Lycopersicon esculentum Mill. cv. Hausu Momotaro.) were used for the short term and long term experiments in the NFT system and in the pot culture system, and maize plants (Zea mays $\mathrm{L}$. cv. Pioneer 1158) were used for measuring root hydraulic conductance by the high pressure flow meter. Seeds of tomato plants were sown in cell trays filled with vermiculite in a growth chamber. At 28 days after sowing (DAS), two tomato plants were cultivated in 2-L pot for the pot culture system experiment. For the NFT system experiment, 25 tomato plants at 45 DAS were transplanted to the NFT bed and cultivated in the greenhouse. Two weeks later, the main shoot was pinched at two leaves above the first truss for the single truss tomato cultivation. Maize plants were sown in $15 \mathrm{~cm}$-pots filled with vermiculite and cultivated in the greenhouse until 40 DAS.

In the NFT system, the high root temperature of $35^{\circ} \mathrm{C}$ and the optimum root temperature of $22^{\circ} \mathrm{C}$ were applied for four weeks. In the pot culture system, different root temperatures of 20,35 and $40^{\circ} \mathrm{C}$ were applied for seven days. And different root temperatures of 10,25 and $40^{\circ} \mathrm{C}$ were applied in the high pressure flow meter with a pressure tank. The standard nutrient solution with an electric conductivity $(E C)$ of $1.0 \mathrm{dSm}^{-1}$ was used for tomato plants and $E C$ of $3.5 \mathrm{dSm}^{-1}$ was used for maize plants.

\section{Results and Discussion}

Figure 1 shows diurnal changes in solar irradiance and uptake rates of water, nitrate and calcium by roots of tomato plants grown under the high $\left(35^{\circ} \mathrm{C}\right)$ and the optimum $\left(22^{\circ} \mathrm{C}\right)$ root temperature in the NFT system on a fine day. Water uptake rate varied with irradiance on a fine day, and the high root temperature enhanced water uptake during the daytime (Fig.1A and B). Nitrate uptake rate varied depending on water uptake rate, and the high root temperature increased nitrate uptake rate in the daytime (Fig.1C), but calcium uptake rate decreased in the afternoon (Fig.1D).

Figure 2 shows the relationship between root temperature and root hydraulic conductance of the maize plants measured in the pressure tank. Root hydraulic conductance was higher at the higher root temperatures, and $Q_{10}$ for the root hydraulic conductance was equal to 1.21 in the temperature range of 10 to $40^{\circ} \mathrm{C}$.

The increased water and nutrients uptake rates and the low value of $Q_{10}$ found in the root hydraulic conductance can be considered to be attributed to the lower viscosity of the nutrient solution under the higher temperatures. These results suggest that the short term effects of the high root temperature are mainly brought through the physical process.
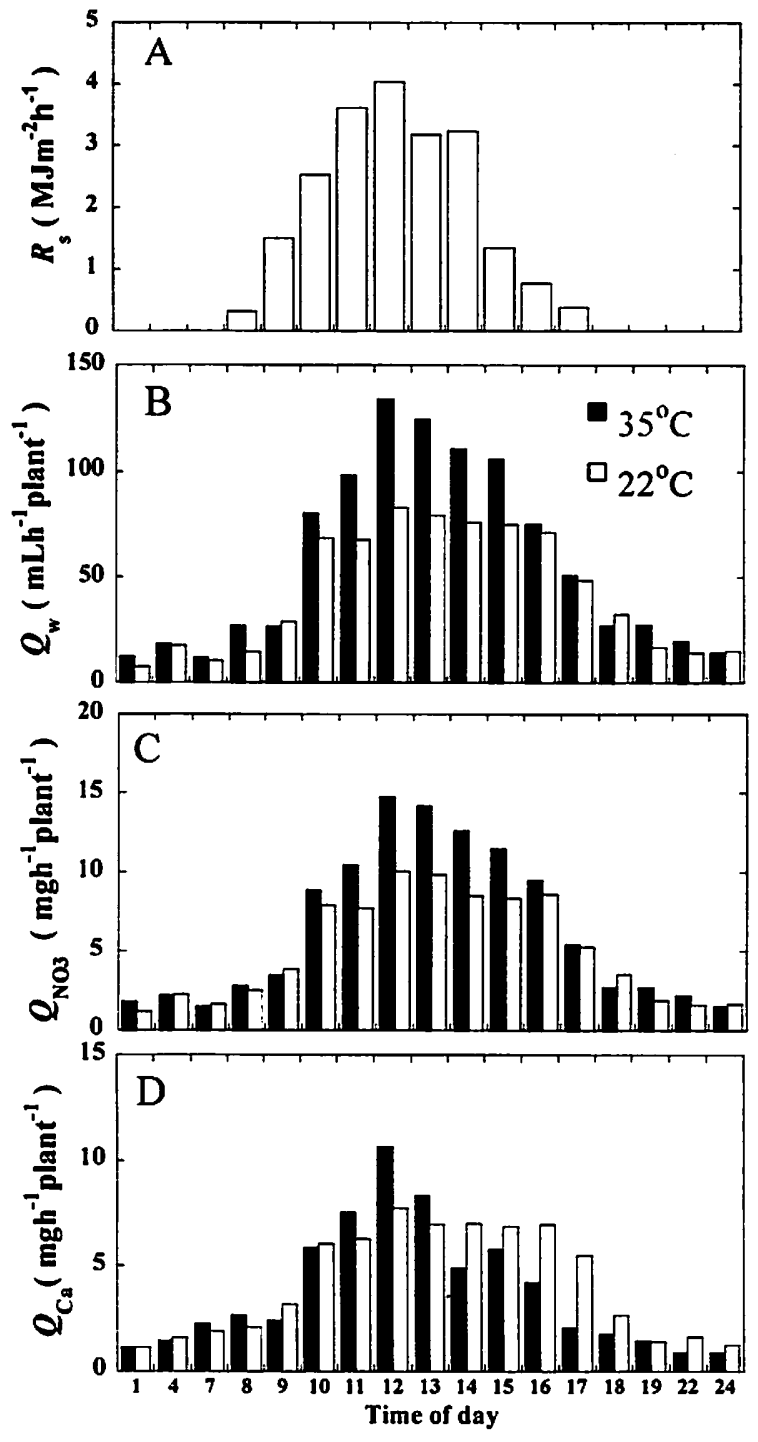

Fig. 1. Diurnal changes in rates of water uptake $\left(Q_{w}\right)$, nitrate uptake $\left(Q_{\mathrm{NO3}}\right)$ and calcium uptake $\left(Q_{\mathrm{Ca}}\right)$ by roots of tomato plants growing in the NFT system on a fine day (7 January) at different root temperatures of $35^{\circ} \mathrm{C}$ and $22^{\circ} \mathrm{C}$. Integrated solar radiation $(R \mathrm{~s})$ is also shown. 


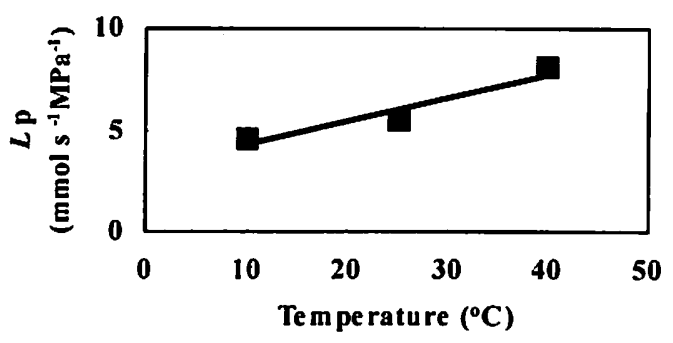

Fig. 2. Root hydraulic conductance $(L p)$ at different root temperatures of 10,25 and $40{ }^{\circ} \mathrm{C}$.

Figure 3 shows weekly changes in water uptake rate and uptake rate and xylem sap concentration of nitrate and calcium of tomato plants grown under the high $\left(35^{\circ} \mathrm{C}\right)$ and the optimum $\left(22^{\circ} \mathrm{C}\right)$ root temperatures in the NFT system for five weeks. Just after the start of the high root temperature treatment, water uptake rate was increased, but one week later the water uptake was depressed (Fig. 3A). The lower dependency of the water uptake rate on irradiance was found in the long term effect of the high root temperature (Table 1). Nutrients $\left(\mathrm{NO}_{3}^{-}\right.$and $\left.\mathrm{Ca}^{2+}\right)$ uptake rates varied depending on water uptake rate (Fig.3B and C). The high root temperature also enhanced nutrients uptake just after the start of the high temperature treatment, but about one week later the nutrients uptake as well as water uptake was depressed by the high root temperature. The high dependency of nutrients uptake rate on water uptake rate was found (Table 1). Nutrients concentration in xylem sap remained almost stable at the optimum temperature, but these xylem sap concentrations became lower by the long term treatment with the high root temperature (Fig.3D and E). These patterns of the short term and the long term effects of the high root temperature in the NFT system were also found in the pot culture system (Fig.4).

Compared with concentration in the solution of the NFT system, the xylem sap concentrations of $\mathrm{NO}_{3}{ }^{-}$and $\mathrm{Ca}^{2+}$ were higher. This indicates that the active processes of $\mathrm{NO}_{3}^{-}$uptake and $\mathrm{Ca}^{2+}$ uptake driven by the transporter and the proton pump (White, 2001; Glass, et al., 2002) play important roles in root uptake of nitrate and calcium. In the long term effect of the high temperature, $\mathrm{NO}_{3}{ }^{-}$and $\mathrm{Ca}^{2+}$ concentrations in xylem sap were clearly decreased, although $\mathrm{NO}_{3}{ }^{-}$ and $\mathrm{Ca}^{2+}$ concentrations in the solution increased to concentrations higher than those in the xylem sap (Fig.3D and E). This indicates that the active processes of nitrate and calcium uptake can be retarded by high root temperature.

Furthermore, growth depression and color change in roots were also caused several days after the high root temperature treatment, and these can be considered to result in the deterioration in root physiological functions. Those results suggest that the short term and the long term effects of high root temperature can appear in different manners through different processes.
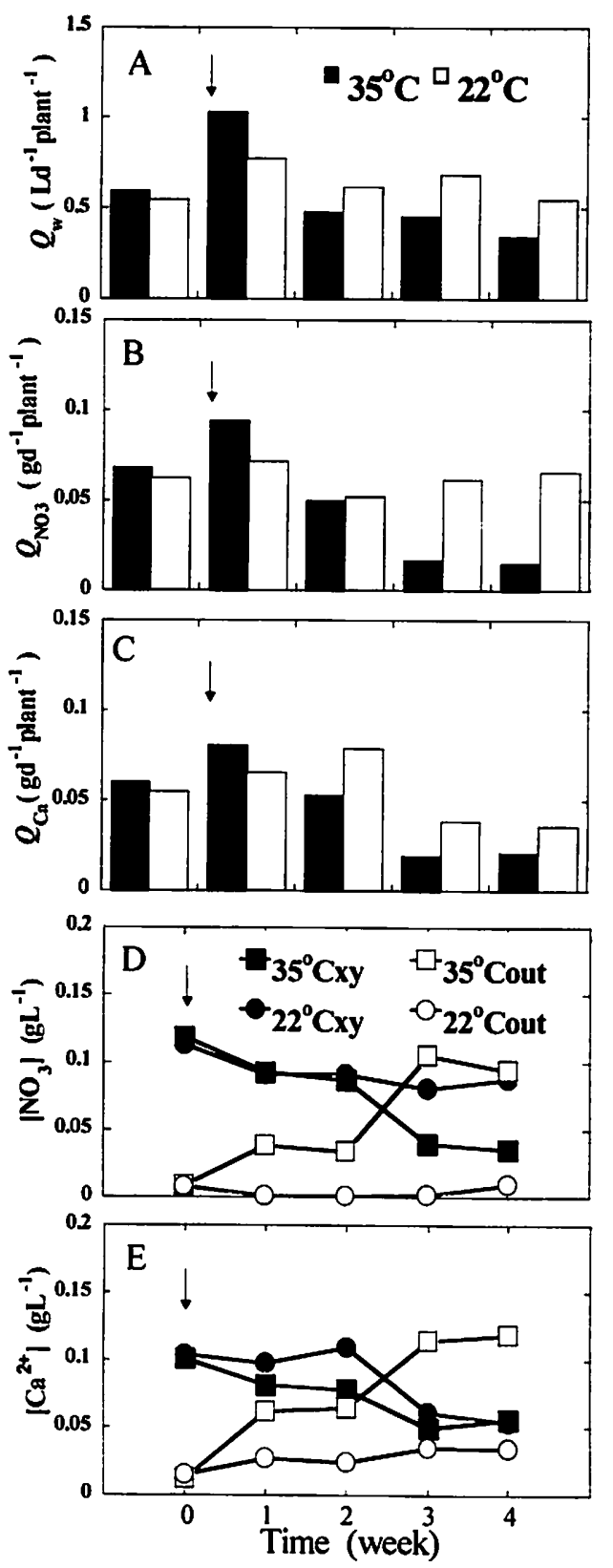

Fig. 3. Weekly changes in rates of water uptake $\left(Q_{\mathrm{w}}\right)$, nitrate uptake $\left(Q_{\mathrm{NO}_{3}}\right)$ and calcium uptake $\left(Q_{\mathrm{Ca}}\right)$ and concentration of nitrate $\left[\mathrm{NO}_{3}{ }^{-}\right]$and calcium $\left[\mathrm{Ca}^{2+}\right]$ in xylem sap ( $35 x y$ and 22xy) and in solution of the NFT system (35out and 22out) at different root temperatures of $35{ }^{\circ} \mathrm{C}$ and $22{ }^{\circ} \mathrm{C}$ growing in the NFT system for five weeks. Arrows indicate the start of the high root temperature $\left(35^{\circ} \mathrm{C}\right)$ treatment. 
Table 1. Relationship of water uptake rate $\left(Q_{w}\right)$ with solar radiation $\left(R_{\mathrm{s}}\right)$,and relationship of nitrate uptake rate $\left(Q_{\mathrm{NO} O 3}\right)$ and calcium uptake rate $\left(Q_{\mathrm{Ca}_{\mathrm{a}}}\right)$ with water uptake rate $\left(Q_{\mathrm{w}}\right)$ at different root temperatures of $35^{\circ} \mathrm{C}$ (R-35)and $22^{\circ} \mathrm{C}$ ( R-22) in the long term (5 weeks) analysis in the NFT system .

\begin{tabular}{ccc}
\hline & $\mathrm{R}-35$ & $\mathrm{R}-22$ \\
\hline$Q_{\mathrm{w}}=f\left(R_{\mathrm{s}}\right)$ & $0.027 R_{\mathrm{s}}+0.23$ & $0.041 R_{\mathrm{s}}+0.11$ \\
& $\mathrm{R}^{2}=0.32 * *$ & $\mathrm{R}^{2}=0.85 * *$ \\
$Q_{\mathrm{NO} 3}=f\left(Q_{\mathrm{w}}\right)$ & $0.067 Q_{\mathrm{w}}+0.017$ & $0.065 Q_{\mathrm{w}}+0.038$ \\
& $\mathrm{R}^{2}=0.71^{* *}$ & $\mathrm{R}^{2}=0.74 * *$ \\
$Q_{\mathrm{Ca}}=f\left(Q_{\mathrm{w}}\right)$ & $0.049 Q_{\mathrm{w}}+0.055$ & $0.063 Q_{\mathrm{w}}+0.029$ \\
& $\mathrm{R}^{2}=0.61 * *$ & $\mathrm{R}^{2}=0.65^{* *}$ \\
\hline
\end{tabular}

${ }^{* *}$, significant level of 0.05 .

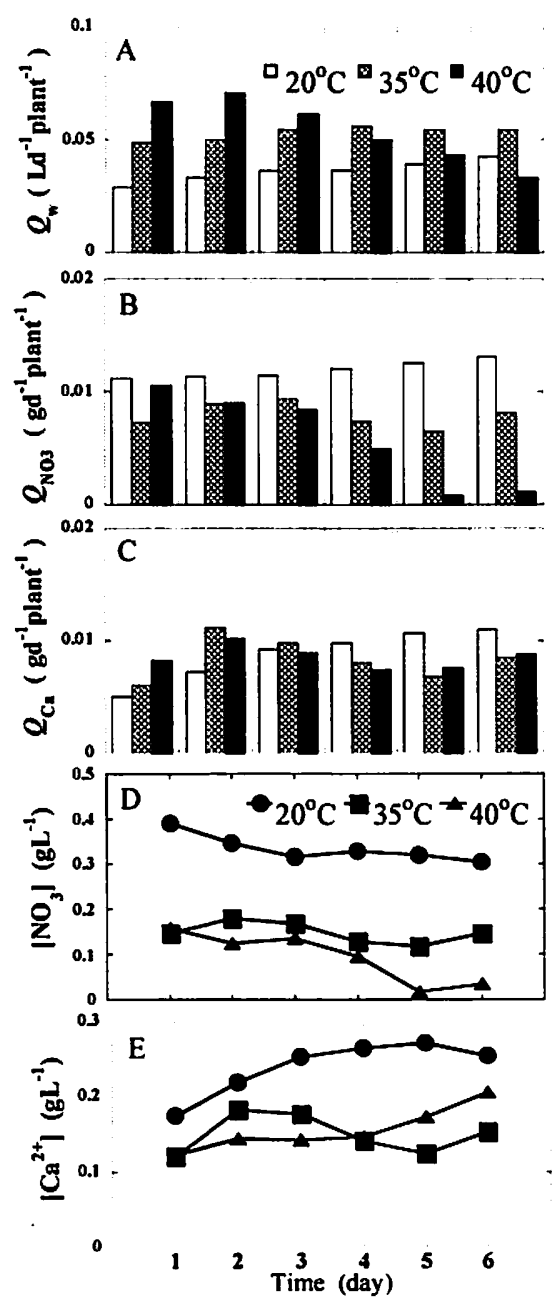

Fig. 4. Time courses of daily integrated water uptake rate $\left(Q_{\mathrm{w}}\right)$, nitrate uptake rate $\left(Q_{\mathrm{NO} O 3}\right)$ and calcium uptake rate $\left(Q_{\mathrm{C}_{\mathrm{a}}}\right)$ and nutrients concentration of $\left[\mathrm{NO}_{3}{ }^{-}\right]$and $\left[\mathrm{Ca}^{2+}\right]$ in xylem sap at different root temperatures of 20,35 and $40{ }^{\circ} \mathrm{C}$ growing in the pot culture system.

\section{References}

Glass, A., Dev, P.M., Brent, T.B., James, N. K., Hebert, R. K., Anshuman, J.K, Mamoru, K., Suman, O. R., Siddiqi, M.Y., Shiela, E. U., and Joseph, J., V. 2002: The Regulation of Nitrate and Ammonium Transport Systems in Plants. J.Exp.Botany., 53, No. 370, 855-864.

Kramer, P.J., and Boyer, J.S., 1995: Water Relations of Plants and Soils. Academic Press, San Diego, pp 495.

Levitt, J., 1980: Responses of Plants to Environmental Stresses, Vol. 1: Chilling, Freezing and High Temperature Stresses. Academic Press, New York, pp 447.

Marschner, H.1995: Mineral Nutrition of Higher Plants, $2^{\text {nd }}$ edition. Academic Press, San Diego, pp 680.

White, P.J. 2001: The Pathways of Calcium Movement to The Xylem. J.Exp.Botany., 52, No.358, 891-899.

Yasutake, D., Kitano, M., Yasunaga, T., Wajima, T., Affan, M. F. F, Hamakoga, M., and Maki, T. 2004 : Dynamic Evaluation of Uptake of Water and Mineral Nutrients by Roots (Japanese text with English Summary) Eco-Engineering., 16 (3), 215-222. 